\title{
Synthesis, Characterization and Biological Studies of Ether-Based Ferrocenyl Amides and their Organic Analogues
}

\author{
Sana Waseem Abbasi ${ }^{1}$, Naveed Zafar Ali ${ }^{2}$, Martin Etter ${ }^{3, *}$, Muhammad Shabbir ${ }^{1}$, \\ Zareen Akhter ${ }^{1, *}$, Stacey J. Smith ${ }^{4}$, Hammad Ismail ${ }^{5}$ and Bushra Mirza ${ }^{6}$ (i) \\ 1 Department of Chemistry, Quaid-i-Azam University, Islamabad 45320, Pakistan; \\ sanawaseem511@gmail.com (S.W.A.); shabbir_chemist@yahoo.com (M.S.) \\ 2 National Centre for Physics, Quaid-i-Azam University, Islamabad 44000, Pakistan; nzafar@ncp.edu.pk \\ 3 Deutsches Elektronen-Synchrotron (DESY), 22607 Hamburg, Germany \\ 4 Department of Chemistry \& Biochemistry, Brigham Young University, Provo, UT 84604, USA; \\ ssmith@chem.byu.edu \\ 5 Department of Biochemistry \& Molecular Biology, University of Gujrat, Gujrat 50700, Pakistan; \\ hammad.ismail@uog.edu.pk \\ 6 Department of Biochemistry, Quaid-i-Azam University, Islamabad 45320, Pakistan; bushramirza@qau.edu.pk \\ * Correspondence: martin.etter@desy.de (M.E.); zareen_a@qau.edu.pk (Z.A.); Tel.: +49-(0)-40-8998-5648 (M.E.); \\ +92-(0)51-90642111 (Z.A.); Fax: +92-(0)51-9064224 (Z.A.)
}

Received: 22 April 2020; Accepted: 2 June 2020; Published: 4 June 2020

\begin{abstract}
Ferrocenyl amides (FB1-FB13) and their organic analogues (BZ1-BZ13) were prepared by a low-temperature condensation method. Ferrocenyl amides were synthesised using 4-ferrocenylbenzoyl chloride and ether-based amines and diamines. Benzoyl chloride was used to synthesise organic analogues by reacting with various amines. The synthesised compounds were characterised by elemental, spectroscopic (FT-IR and NMR) and single crystal X-ray diffraction methods. Crystal structures of the representative organic analogues (BZ2 and BZ6) were solved by single crystal X-ray diffraction. BZ2 crystallises in the triclinic space group $P \overline{1}$ with a unit cell volume of $V=1056.6(3) \AA^{3}$ and with two formula units per unit cell. Whereas BZ6 assembles in the orthorhombic space group Pbca with four formula units per unit cell and a unit cell volume of $V=1354.7(2) \AA^{3}$. Spectral studies confirmed the presence of amide linkages in the synthesised compound with a strong $\mathrm{N}-\mathrm{H} \cdots . . \mathrm{O}=\mathrm{C}$ hydrogen bonding network established between amide groups of neighbouring molecular scaffolds further stabilising the molecular stacking in accordance with the archetypal crystal structures. The bioactive nature of each compound was assessed by DPPH (2,2-diphenyl-1-picrylhydrazyl) free radical scavenging activity, hydrogen peroxide scavenging activity and total antioxidant activity. Antidiabetic, anticholinesterase enzyme inhibition tests, as well as antibacterial activities, were performed showing significant biological activity for ferrocenyl amides as compared to their organic analogues.
\end{abstract}

Keywords: ferrocenyl amides; organic amides; biological activities

\section{Introduction}

Ferrocene has gained immense importance among the metallocenes because of its unique properties and wide range of applications. The ferrocene derivatives are recognised for their stability in the biological medium and for their lipophilic, nontoxic, and reversible redox properties [1-3]. Ferrocene has a wide variety of applications from antiknock agents to polymerisation catalysts. Due to the favourable electronic properties of ferrocene derivatives and their easy functionalisation, these compounds have a wide range of applications in material science including sensors, catalytic materials, electroactive 
materials and aerospace materials [4,5]. Ferrocene and its derivatives can also be utilised as efficient medicinal substances for novel drug discovery. Furthermore, the electrochemical properties of ferrocene containing nucleic acids can be utilised for bioelectronics and glucose biosensors [6,7]. Ferrocenyl analogues of tamoxifen also show potential activity against hormone-dependent cancer cells as well as hormone-independent cancer cells for which tamoxifen is biologically inactive [8]. Other primary attributes of ferrocene are its non-cytotoxicity to human cells, stability in aqueous media, aromaticity, tunable redox activity and its potential to form reactive oxygen species. Ferrocene is also known to undergo reversible single-electron oxidation to the ferrocenium cation that prompts subsequent adjustment in hydrogen bonding interactions that results in a redox-dependent conformational switch. The synthetic systems that show conformational dynamism in response to oxidation state are finding increasing application in solid-state electronic devices and sensors [7,9].

Amides are very important to sustain life as they are the building blocks of proteins which make up our systems. Amides play a major role in natural products and agrochemicals. The structures of amides show that electrons are delocalised over the $\mathrm{N}-\mathrm{C}-\mathrm{O}$ bond. Due to this property secondary structures are formed in proteins. The flexibility of the peptide bond facilitates both cis and trans conformations, however, trans conformation is observed more owing to its greater stability [10]. Amide gets resonance stabilised due to intensive conjugation which renders it more resistant towards nucleophilic agents and in ascertaining its chemical reactivity [11,12]. Aromatic amides have significant applications in the field of pharmaceuticals, especially bis-benzamides are active anti-inflammatory agents [13]. Amide bonds have a greater contribution to biological systems as they play an important role in drug molecular design [14]. Amides like teduglutide and linaclotide are used to treat gastrointestinal disorders, respiratory distress syndrome in premature infants is prevented using lucinactant which is a lung surfactant. Dialysis patients suffering from anaemia can be treated using peginesatide. Pasireotide is used to treat adult patients with Cushing's disease with no surgical option and Carfilzomib is a treatment for haematological cancer [15].

Among others, ferrocenyl amides have attracted a lot of attention due to their inherent ability to form supramolecular assemblies through non-covalent interactions, namely hydrogen bonding [16]. With the onset of external stimulus, the strength and selectivity of hydrogen bonded interactions in synthetic host-guest systems can be reversibly modulated mimicking biological systems, that plays a pivotal role in dictating the properties of natural and synthetic materials. In such assemblies, the amide linkage in the chain provides orientation stability and hydrogen bonding that further increases the mechanical strength of the assembly [17]. Similar studies on ferrocenyl amide systems show that the oxidation of ferrocene withdraws electron density from the neighbouring amide $\mathrm{NH}$ bond resulting in a stronger H-bond donor. Hydrogen bonding in ferrocenyl amides can also be utilised to form hydrogen-bonded templates which effectively transfer electrons along the intermolecular hydrogen bonds. Their redox potential is lowered due to the presence of the aromatic linker between ferrocene and the peptide unit.

The potential at which ferrocene is interconverted to a ferrocenium cation lies in the range of biologically accessible potentials [9]. Thus, incorporation of a ferrocene moiety into a bioactive organic molecule often imparts biological activity because of different membrane permeation properties and anomalous metabolism, consequently considered as an appealing strategy to find new compounds for the treatment of various ailments [18]. For instance, consider the precedent of protein functionality in biological systems modulated through the redox-sensing switches of cysteine and disulfide bond. Understanding the intrinsic conformational dynamism within the protein structure is essential to the survival of living organisms. Cysteine plays structural and regulatory roles and in particular, the thiol side chain in cysteine groups can undergo numerous modifications, making cysteine a unique molecular switch that often provokes mutations in the amino acid sequence and can ultimately trigger disease [18]. These natural mechanisms of control inspired us to inspect the preliminary structure-activity relationship in the analogous synthetic systems that can transform the H-bonded scaffold into a redox-dependent switch. 
In the present investigation, we have synthesised a series of ferrocenyl amides (FB1-FB13) and their organic analogues (BZ1-BZ13). The crystal structure of two of the representative compounds namely BZ2 and BZ6 were determined via single crystal X-ray diffraction analyses. Elemental and spectroscopic (FT-IR and NMR) techniques further validated the structural model of all the compounds stabilised by a strong hydrogen bonding network between the amide groups of neighbouring molecular stacking. The compounds under investigation showed profound bioactivity which was analysed via free radical and $\mathrm{H}_{2} \mathrm{O}_{2}$ scavenging activity, total antioxidant activity, enzyme inhibition, and antibacterial activity. A significant thrust in biological activities was also observed for pristine ferrocenyl amides when compared with organic analogues.

\section{Materials and Methods}

\subsection{Reactants and Instrumentation}

For the synthesis of amides, all the reagents and chemicals used were of analytical grade. Ferrocene, hexadecyltrimethylammonium bromide (PTC), hydrogen chloride, 4-amino benzoic acid, triethylamine, $n$-hexane and sodium nitrate were purchased from Fluka, Buchs, Switzerland. Aniline, thionyl chloride, diethyl ether, acetone, chloroform, ethyl acetate, dimethyl sulfoxide (DMSO), dichloromethane and methanol were acquired from Merck, Darmstadt, Germany. Benzoyl chloride was obtained from Panreac, Castellar del Vallès, Spain. Ethanol, $N, N$-dimethyl formamide (DMF) and tetrahydrofuran (THF) were purchased from Riedel-de Haen, Seelze, Germany. The reactions were carried out in an inert atmosphere of nitrogen. Synthetic progress of the ferrocene-based amides and their organic analogues were monitored by thin layer chromatography.

Melting points of the synthesised compounds were determined using an MPD Mitamura Riken Kogyo (Japan) electrothermal melting point apparatus. FTIR spectra were recorded on a Bruker Tensor II (Germany) spectrometer in the frequency range of $4000-400 \mathrm{~cm}^{-1} \cdot{ }^{1} \mathrm{H}$ NMR $(300 \mathrm{MHz})$ and ${ }^{13} \mathrm{C}$ NMR $(75 \mathrm{MHz})$ spectra were recorded on a Bruker NMR Spectrometer.

Single crystal X-ray diffraction analyses were performed for the structural elucidation and conformational analysis of the organic analogues BZ2 and BZ6. Low-temperature (100 K) X-ray diffraction data comprising $\varphi$ - and $\omega$-scans were collected using a MACH3 kappa goniometer coupled to a Bruker Apex II CCD detector with a Bruker-Nonius FR591 rotating anode X-ray source producing $\mathrm{Cu} \mathrm{K} \alpha$ radiation $(\lambda=1.54178 \AA)$. The Bruker APEX3 suite was used to process the data; reflection intensities were integrated through the program SAINT, and appropriate absorption corrections were applied to the intensities via a multi-scan method using the program SADABS.

The structures were solved using dual-space methods in SHELXT [19] and refined against F2 on all data by full-matrix least squares with SHELXL-2014 [20] using established refinement strategies [21]. All non-hydrogen atoms were refined anisotropically. The positions of all hydrogen atoms bound to carbon were calculated geometrically and refined using a riding model. The positions of hydrogen atoms bound to nitrogen groups were taken from the difference Fourier synthesis and subsequently refined semi-freely with the help of appropriate distance restraints. The isotropic displacement parameters of all hydrogen atoms were constrained to be 1.2 times the Ueq value of the atom to which they are bound. Details of the crystal structures of compounds BZ2 and BZ6 are listed in Table 1.

\subsection{Biological Activity}

For DPPH free radical scavenging activity, $10 \mu \mathrm{L}$ of sample solution $(1000 \mu \mathrm{g} / \mathrm{mL})$ was added to $190 \mu \mathrm{L} \mathrm{DPPH}(150 \mu \mathrm{M})$ in DMSO and incubated for $30 \mathrm{~min}$ at $37^{\circ} \mathrm{C}$. The control solution contained DPPH without the sample. The absorbance of the mixture was measured at $517 \mathrm{~nm}$ that decreased due to the quenching of DPPH free radicals and the percentage of inhibition was calculated [22].

For total antioxidant activity, $100 \mu \mathrm{L}$ of sample and $3.9 \mathrm{~mL}$ of reagent solution $\left(0.6 \mathrm{M} \mathrm{H}_{2} \mathrm{SO}_{4}\right.$, $28 \mathrm{mM}$ sodium phosphate, $4 \mathrm{mM}$ ammonium molybdate) were mixed and boiled at $95^{\circ} \mathrm{C}$ for $90 \mathrm{~min}$ 
and the absorbance was measured at $695 \mathrm{~nm}$. The control solution contained the reagent without the sample [16].

For hydrogen peroxide scavenging activity, $100 \mu \mathrm{L}$ of sample solution was mixed with $\mathrm{H}_{2} \mathrm{O}_{2}$ $(2.4 \mathrm{~mL}, 4 \mathrm{mM})$ in phosphate buffer $(\mathrm{pH}=7,0.1 \mathrm{M})$. Incubation was done at room temperature for $10 \mathrm{~min}$ and absorbance was taken at $230 \mathrm{~nm}$ against a blank solution.

In the case of alpha amylase enzyme inhibition activity, $1.2 \mathrm{~mL}$ of starch in phosphate buffer containing $6.7 \mathrm{mM}$ of $\mathrm{NaCl}$ was added to $600 \mu \mathrm{L}$ of the sample stock (50, 100, $200 \mathrm{ppm}$ ). The reaction was initiated by adding $600 \mu \mathrm{L}$ porcine pancreatic amylase and incubated at $37^{\circ} \mathrm{C}$. This mixture along with reagent solution [ $1 \mathrm{~g}$ of DNSA (3,5-dinitrosalicylic acid), $30 \mathrm{~g}$ of potassium tartrate and $20 \mathrm{~mL}$ of $\mathrm{NaOH}(2 \mathrm{~N})]$ was prepared in distilled water and was kept in a hot water bath for $15 \mathrm{~min}$. The reaction mixture was diluted with water $(2.7 \mathrm{~mL})$ and the absorbance was evaluated at $540 \mathrm{~nm}$ [22].

In the alpha glucosidase enzyme inhibition assay, alpha glucosidase was dissolved in 0.1 units $/ \mathrm{mL}$ of buffer A $\left[(0.1 \mathrm{~mol} / \mathrm{L})\right.$ potassium phosphate, $\left.(3.2 \mathrm{mmol} / \mathrm{L}) \mathrm{MgCl}_{2},(\mathrm{pH}=6.8)\right] .6 \mathrm{mmol} / \mathrm{L}$ p-nitrophenylglucopyranoside was prepared in the same buffer $(\mathrm{pH}=6.8) .102 \mu \mathrm{L}$ of buffer $\mathrm{B}$ was prepared using $5 \mathrm{~mol} / \mathrm{L}$ potassium phosphate, $16 \mathrm{mmol} / \mathrm{L} \mathrm{MgCl}_{2}$ having a $\mathrm{pH}$ of 6.8 . The sample $(0.6 \mathrm{mg} / \mathrm{mL})$ was prepared in DMSO. Sample solution along with buffer A, $282 \mu \mathrm{L}$ of water and $200 \mu \mathrm{L}$ of substrate were mixed. The mixture was incubated for $5 \mathrm{~min}$ at $37^{\circ} \mathrm{C}$ and then the enzyme solution $(200 \mu \mathrm{L})$ was added. This reaction was carried out for $30 \mathrm{~min}$ and then glycine buffer was added to terminate the reaction. The absorbance was subsequently measured at $410 \mathrm{~nm}$ [23].

For butyrylcholinesterase enzyme inhibition activity, the enzyme was prepared in phosphate buffer (pH 8.0) along with $100 \mathrm{mM}$ of sodium phosphate buffer $(180 \mu \mathrm{L})$. Ellman's reagent (DTNB, 5-5-dithio-bis[2-nitrobenzoic acid] prepared in buffer $(10 \mu \mathrm{L})$ and sample solution $(10 \mu \mathrm{L})$ were added to each of the solutions. All these solutions were mixed well and incubated for $15 \mathrm{~min}$ at $25^{\circ} \mathrm{C}$. The reaction started upon the addition of $10 \mu \mathrm{L}$ of substrate solution (butyrylcholine iodide, $10 \mathrm{mM}$ ) and absorbance was taken at $412 \mathrm{~nm}$ after $10 \mathrm{~min}$ [23].

For acetylcholinesterase enzyme inhibition activity, enzyme (100 $\mathrm{U}$ [enzyme unit $(\mathrm{U})=1 \mu \mathrm{mol} \mathrm{min}{ }^{-1}$ ]) was dissolved in tris-hydrochloric acid buffer of $\mathrm{pH}$ 7.8. Bovine serum albumin was added to stabilise this solution. TLC plates were loaded with sample solution $(0.01-1000 \mathrm{ng} / \mathrm{spot})$ and sprayed with the solution of the enzyme $(3.33 \mu / \mathrm{mL})$. These plates were dried and incubated for $20 \mathrm{~min}$ at $37^{\circ} \mathrm{C}$. A solution of 1-naphthyl acetate $(0.25 \%)$ in ethanol and $0.25 \%$ of Fast Blue B salt $(20 \mathrm{~mL})$ was sprayed on the plates to detect the enzyme activity. Inhibitors of these enzymes appeared as clear zones on purple coloured background [24].

For antibacterial activity, the agar diffusion disc-variant method was employed. Different dilutions of sample solution $100,80,60,40 \mathrm{mg} / \mathrm{mL}$ were prepared. Whatman filter paper no.3 $(7 \mathrm{~mm})$ was impregnated with different dilutions of the sample solution $(20 \mathrm{~mL})$. Diluent was evaporated at room temperature and was refrigerated for further use. These paper discs were placed on the surface of agar while Kanamycine was used as a positive control [25].

\subsection{Synthesis of 4-Ferrocenyl Benzoic Acid}

4-Amino benzoic acid ( $7 \mathrm{~g}, 50 \mathrm{mmol})$ was dissolved in a mixture of water $(80 \mathrm{~mL})$ and concentrated hydrochloric acid $(12 \mathrm{~mL})$ at $0-5^{\circ} \mathrm{C}$ in a two necked round bottom flask. A solution of sodium nitrite $(3.5 \mathrm{~g}, 50 \mathrm{mmol})$ was prepared in water $(20 \mathrm{~mL})$ and dropwise addition of this solution was done to the above-mentioned mixture with a stirring of $30 \mathrm{~min}$. The product formed was diazonium salt which was kept at low temperature $\left(5^{\circ} \mathrm{C}\right)$ for further use. In a two necked round bottom flask, ferrocene $(10 \mathrm{~g}, 50 \mathrm{mmol})$ was dissolved in diethyl ether $(100 \mathrm{~mL})$ at $0{ }^{\circ} \mathrm{C}$ along with the addition of $0.5 \mathrm{~g}$ of hexadecyltri-methylammonium bromide (PTC) with stirring. Diazonium salt was added dropwise at low temperature. This reaction mixture was stirred for $24 \mathrm{~h}$ after the completion of the reaction. Diethyl ether was evaporated and a dark brown solid was obtained which was dissolved in distilled water $(500 \mathrm{~mL})$ containing $\mathrm{NaOH}(5 \mathrm{~g})$ at $90^{\circ} \mathrm{C}$. This mixture was filtered hot. Unreacted ferrocene was recovered as a result of this filtration. Upon cooling of the filtrate, dark brown precipitates of 
4-ferrocenyl benzoic acid were obtained by gradual addition of $\mathrm{HCl}$ which was filtered off and washed several times with water. Yield $=64 \%, \mathrm{~m} . \mathrm{p} .=240-241^{\circ} \mathrm{C}$ (decomposition).

\subsection{Synthesis of 4-Ferrocenyl Benzoyl Chloride}

4-Ferrocenyl benzoic acid ( $5 \mathrm{~g}$, $20 \mathrm{mmol})$ dissolved in THF $(200 \mathrm{~mL})$ was added to a two-necked round bottom flask containing magnetic stirrer and attached to a vacuum line assembly under inert conditions. The temperature was kept low $\left(57^{\circ} \mathrm{C}\right)$ and SOCl2 $(14.5 \mathrm{~mL}, 20 \mathrm{mmol})$ was added dropwise with continuous stirring for $3 \mathrm{~h}$. After the completion of the reaction, THF was rotary evaporated and the solid product obtained was dissolved in diethyl ether which was separated using cannula filtration. Diethyl ether was evaporated and a dark brown solid i.e., ferrocenyl benzoyl chloride was obtained [26] (Scheme 1).

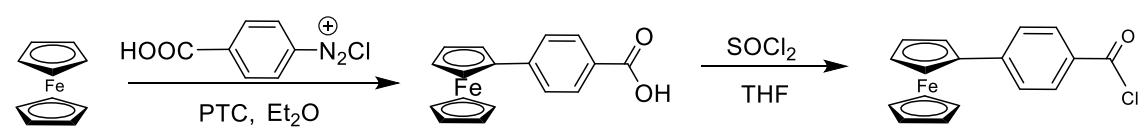

Scheme 1. Synthesis of 4-ferrocenyl benzoyl chloride.

\subsection{Synthesis of Ferrocenyl Amides (FB1-FB13)}

In a two-necked flask equipped with magnetic stirrer and condenser, $0.5 \mathrm{~g}(1.80 \mathrm{mmol})$ of respective amine was taken. A mixture of THF $(10 \mathrm{~mL})$ and triethylamine $(10 \mathrm{~mL})$ was added to the flask at freezing temperature in an ice bath. Acid chloride dissolved in THF was added dropwise to this reaction mixture while stirring for $24 \mathrm{~h}$. Salts were removed after the completion of the reaction by filtration. The solvent was removed by rotary evaporator and a non-solvent (n-hexane) was added to get the product (Scheme 2).

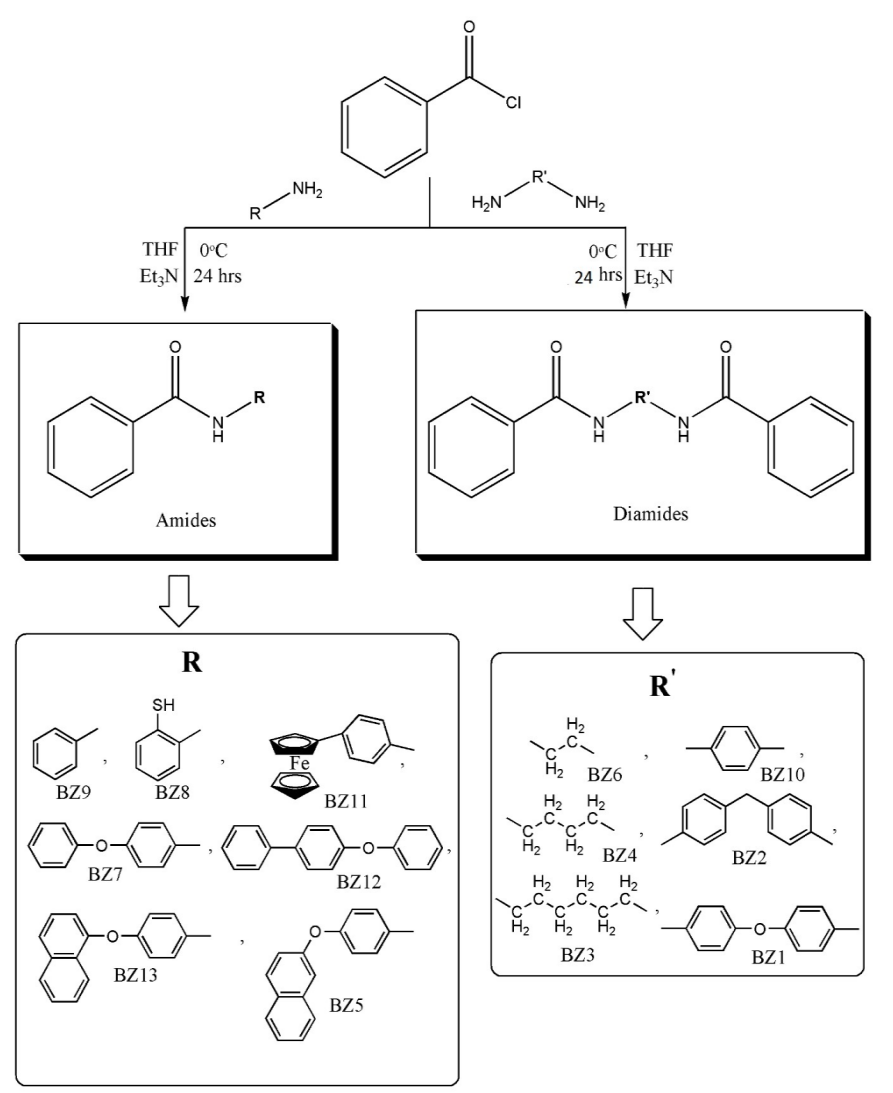

Scheme 2. Synthesis of ferrocenyl amides (FB1-FB13). 


\subsection{Synthesis of Organic Analogues (BZ1-BZ13)}

In a $500 \mathrm{~mL}$ two-necked flask, respective amines $(1.8 \mathrm{mmol})$, THF $(10 \mathrm{~mL})$ and triethylamine $(10 \mathrm{~mL})$ were added at $0{ }^{\circ} \mathrm{C}$ in an ice bath. Benzoyl chloride $(1.8 \mathrm{mmol})$ was added to the reaction mixture and stirring was done for $24 \mathrm{~h}$. Completion of the reaction was monitored by TLC. After the completion of the reaction, the reaction mixture was filtered to remove salts. The solvent was removed under vacuum and non-solvent (n-hexane) was added to get the product. All organic analogues were synthesised employing the procedure as depicted in Scheme 3.

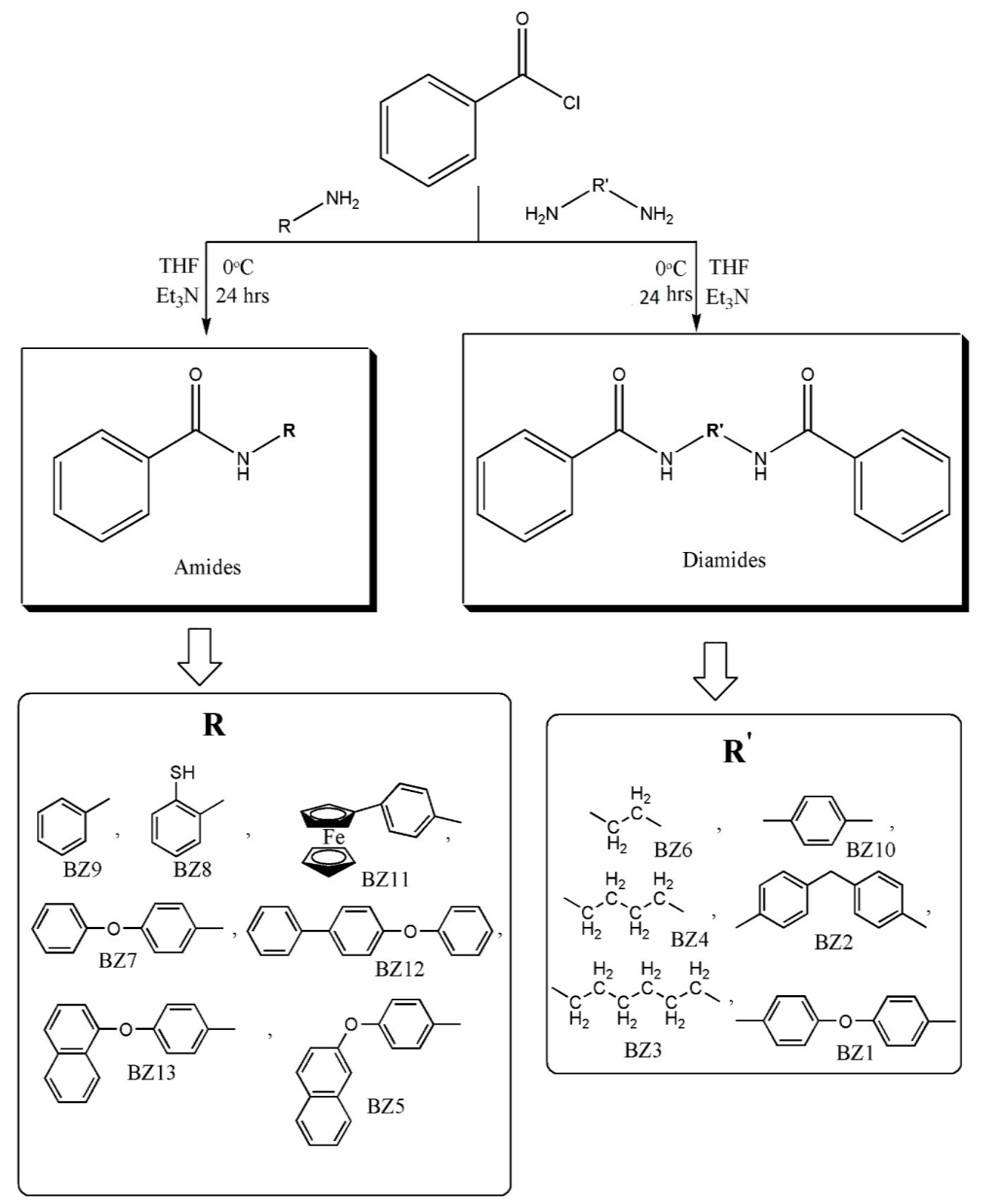

Scheme 3. Synthesis of organic analogues (BZ1-BZ13). 


\section{Results and Discussion}

Two series of amides, i.e., ferrocenyl amides (FB1-FB13) and their organic analogues (BZ1-BZ13) were synthesised using benzoyl chloride and 4-ferrocenyl benzoyl chloride as starting precursors, respectively. Systematic spectroscopic analysis of the synthesised compounds was performed using FTIR, NMR and elemental analysis techniques. The functional group's allotment was in good compliance with the proposed structure elucidated through single crystal X-ray diffraction. Comparison between the biological/antibacterial activity of both series shows a significant biological activity of ferrocene-based amides.

\subsection{Single Crystal X-ray Diffraction Analysis}

Crystal structures of the organic analogues namely BZ2 and BZ6 were determined at a temperature of $100 \mathrm{~K}$ by single crystal X-ray diffraction. At this temperature BZ2 crystallises in the triclinic space group $P \overline{1}$ with lattice parameters $\mathrm{a}=5.7281(9) \AA, \mathrm{b}=9.5981(10) \AA, \mathrm{c}=20.016(3) \AA, \alpha=88.675(9)^{\circ}$, $\beta=82.397(10)^{\circ}$ and $\gamma=75.618(10)^{\circ}$, a unit cell volume of $V=1056.6(3) \AA^{3}$ and with two formula units per unit cell. In contrast to BZ2, BZ6 assembles in the orthorhombic space group Pbca with four formula units per unit cell and lattice parameters of $a=8.9703(9) \AA, b=9.9594(10) \AA, c=15.1634(16) \AA$, and with a unit cell volume of $\mathrm{V}=1354.7(2) \AA^{3}$. Remarkable for the crystal structure of BZ6 is, that a centre of inversion of the unit cell is congruent with the centre of inversion of a single BZ6 molecule, which results in an asymmetric unit cell which consists of only half a molecule. Taking into account the general multiplicity of 8 of the Pbca space group, this results in four complete molecules per unit cell. Further details of the refinements, as well as the R-factors and the goodness-of-fit, can be found in Table 1.

Perspective views of the molecules BZ2 and BZ6 together with riding $\mathrm{H}$-atoms can be found in Figures 1a and 2a, respectively. The molecule geometry of BZ2 consists of four phenyl rings, of which two phenyl rings are planar connected by an amide group. Both groups are then connected by a methylene group which leads to a bend configuration at an angle of $115.6(1)^{\circ}$ and a torsion angle between the phenyl rings of 70.1(2) ${ }^{\circ}$. In the configuration of the BZ6 molecule, a phenyl ring is almost planar linked with an amide group, leading to a benzamide group. Two of these benzamide groups are then connected by an ethylene group both at an angle of $111.8(1)^{\circ}$. This leads finally to a configuration where both benzamide groups are aligned parallel to each other.

The packing scheme of the crystal structure of BZ2 is given by densely stacked BZ2 molecules along the a-direction (Figure 2b), whereas in the b-direction no dense packing of molecules is observed (Figure 2c). In the a-direction phenyl rings of adjacent molecules try to arrange parallel to each other, which is in contrast to the b-direction, where the phenyl rings of adjacent molecules are organised in a more orthogonal manner. The same orthogonal configuration of the phenyl rings of neighbouring molecules can be found in the c-direction. In the b-direction, the stacking is stabilised not only by van-der-Waals interactions but also by a hydrogen bonding network (two-coloured bonds in Figure 2c) which is established between an oxygen atom (acceptor) from the amide group of one molecule to the N-H group (donor group) of the amide group of a neighbouring molecule (for the hydrogen bond distances see Table 2). Since the BZ2 molecule consists of two amide fragments, the most stable configuration along the b-direction can be reached, if the phenyl rings take an orthogonal arrangement as this allows the formation of two hydrogen bonds between the four amide groups of two adjacent molecules. 
For the crystal structure of BZ6, a different packing scheme can be found. In the a-direction, the molecules adopt a dense stacking sequence of parallel aligned molecules, whereas in the c-direction an orthogonal arrangement of adjacent molecules is obtained (Figure $2 b$ ). In the b-direction, the stacking of the molecules is stabilised by a hydrogen bonding network (two-coloured bonds in Figure 2c), which runs along the crystallographic b-axis and which connects the molecules in two adjacent planes orthogonal to the b-direction in a zig-zag-type manner: one amide group of a molecule in plane 1 is hydrogen bonded to the amide group of a neighbouring molecule in plane 2 , whereas the second amide group of the molecule in plane 1 is connected to the amide group of a third molecule, which also lies in plane 2. This zig-zag-type arrangement of the molecules leads to an orthogonal configuration of the molecules in the b-direction and explains also the dense parallel packing along the a-direction. Corresponding bond lengths for the donor-acceptor distances are given in Table 2.

Table 1. Crystal data and structure refinement for BZ2 and BZ6.

\begin{tabular}{|c|c|c|}
\hline Empirical Formula & $\mathrm{C}_{27} \mathrm{H}_{22} \mathrm{~N}_{2} \mathrm{O}_{2}$ & $\mathrm{C}_{16} \mathrm{H}_{16} \mathrm{~N}_{2} \mathrm{O}_{2}$ \\
\hline Formula weight & 406.46 & 268.31 \\
\hline Temperature & $100(2) \mathrm{K}$ & $100(2) \mathrm{K}$ \\
\hline Wavelength & $1.54178 \AA$ & $1.54178 \AA$ \\
\hline Crystal system & Triclinic & Orthorhombic \\
\hline Space group & $P \overline{1}$ & $\mathrm{Pbca}$ \\
\hline Unit cell dimensions & $\begin{array}{c}\mathrm{a}=5.7281(9) \AA, \alpha=88.675(9)^{\circ} \\
\mathrm{b}=9.5981(10) \AA, \beta=82.397(10)^{\circ} \\
\mathrm{c}=20.016(3) \AA, \gamma=75.618(10)^{\circ}\end{array}$ & $\begin{array}{c}\mathrm{a}=8.9703(9) \AA, \alpha=90^{\circ} \\
\mathrm{b}=9.9594(10) \AA, \beta=90^{\circ} \\
\mathrm{c}=15.1634(16) \AA, \gamma=90^{\circ}\end{array}$ \\
\hline Volume & $1056.6(3) \AA^{3}$ & $1354.7(2) \AA^{3}$ \\
\hline $\mathrm{Z}$ & 2 & $4(8$, for asymmetric unit $)$ \\
\hline Density (calculated) & $1.278 \mathrm{Mg} / \mathrm{m}^{3}$ & $1.316 \mathrm{Mg} / \mathrm{m}^{3}$ \\
\hline Absorption coefficient & $0.643 \mathrm{~mm}^{-1}$ & $0.710 \mathrm{~mm}^{-1}$ \\
\hline $\mathrm{F}(000)$ & 428 & 568 \\
\hline Crystal size & $0.280 \times 0.160 \times 0.050 \mathrm{~mm}^{3}$ & $0.340 \times 0.190 \times 0.180 \mathrm{~mm}^{3}$ \\
\hline Theta range for data collection & 4.457 to $68.649^{\circ}$ & 5.836 to $68.333^{\circ}$ \\
\hline Index ranges & $\begin{array}{c}-6<=\mathrm{h}<=6,-11<=\mathrm{k}<=10,-24 \\
<=1<=23\end{array}$ & $\begin{array}{c}-10<=\mathrm{h}<=10,-11<=\mathrm{k}<=11, \\
-18<=1<=17\end{array}$ \\
\hline Reflections collected & 25,227 & 15,989 \\
\hline Independent reflections & $3852[\mathrm{R}(\mathrm{int})=0.0588]$ & $1236[\mathrm{R}(\mathrm{int})=0.0447]$ \\
\hline Completeness to theta $=67.679^{\circ}$ & $99.8 \%$ & $99.9 \%$ \\
\hline Absorption correction & Semi-empirical from equivalents & Semi-empirical from equivalents \\
\hline Refinement method & Full-matrix least-squares on $\mathrm{F}^{2}$ & Full-matrix least-squares on $\mathrm{F}^{2}$ \\
\hline Data/restraints/parameters & $3852 / 2 / 286$ & $1236 / 67 / 95$ \\
\hline Goodness-of-fit on $\mathrm{F}^{2}$ & 1.042 & 1.039 \\
\hline Final $R$ indices $[\mathrm{I}>2 \operatorname{sigma}(\mathrm{I})]$ & $\mathrm{R}_{1}=0.0363, \mathrm{wR}_{2}=0.0904$ & $\mathrm{R}_{1}=0.0308, \mathrm{wR}_{2}=0.0783$ \\
\hline $\mathrm{R}$ indices (all data) & $\mathrm{R}_{1}=0.0450, \mathrm{wR}_{2}=0.0956$ & $\mathrm{R}_{1}=0.0313, \mathrm{wR}_{2}=0.0788$ \\
\hline Extinction coefficient & $\mathrm{n} / \mathrm{a}$ & $0.0046(6)$ \\
\hline Largest diff. peak and hole & 0.166 and $-0.204 \mathrm{e} \cdot \AA^{-3}$ & 0.196 and $-0.159 \mathrm{e} \cdot \AA^{-3}$ \\
\hline
\end{tabular}

Table 2. Hydrogen bonds for BZ2 and BZ6 [̊̊ and $\left.{ }^{\circ}\right]$.

\begin{tabular}{|c|c|c|c|c|c|}
\hline & $\mathrm{D}-\mathrm{H} \cdots \mathrm{A}$ & $d(D-H)$ & $\mathrm{d}(\mathbf{H} \cdots \mathbf{A})$ & $d(D \cdots A)$ & $<$ (DHA) \\
\hline \multirow{2}{*}{ BZ2 } & $\mathrm{N}(1)-\mathrm{H}(1 \mathrm{~N} 1) \cdots \mathrm{O}(2) \# 1$ & $0.900(13)$ & $2.070(13)$ & $2.9358(14)$ & $161.3(13)$ \\
\hline & $\mathrm{N}(2)-\mathrm{H}(1 \mathrm{~N} 2) \cdots \mathrm{O}(1) \# 2$ & $0.899(13)$ & $1.988(13)$ & $2.8742(14)$ & $168.1(14)$ \\
\hline BZ6 & $\mathrm{N}(1)-\mathrm{H}(1 \mathrm{~N} 1) \cdots \mathrm{O}(1) \# 2$ & $0.885(12)$ & $1.965(12)$ & $2.8420(12)$ & $170.5(12)$ \\
\hline
\end{tabular}

Symmetry transformations used to generate equivalent atoms: $\# 1-x+1,-y+2,-z+1 \# 2-x+1,-y+1,-z+1$. 
a)

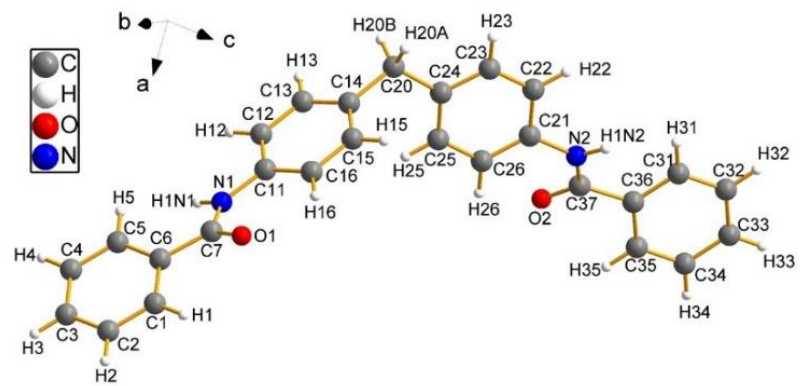

b)

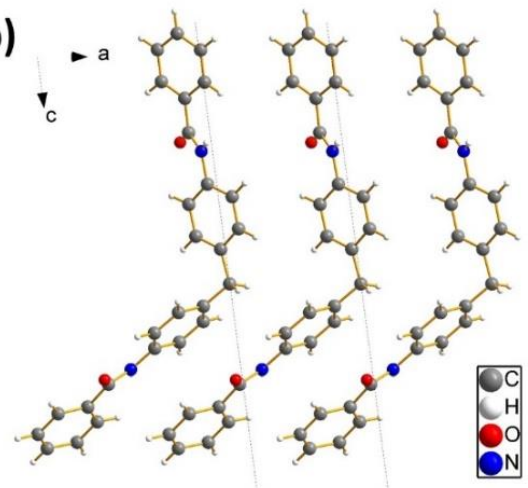

c)

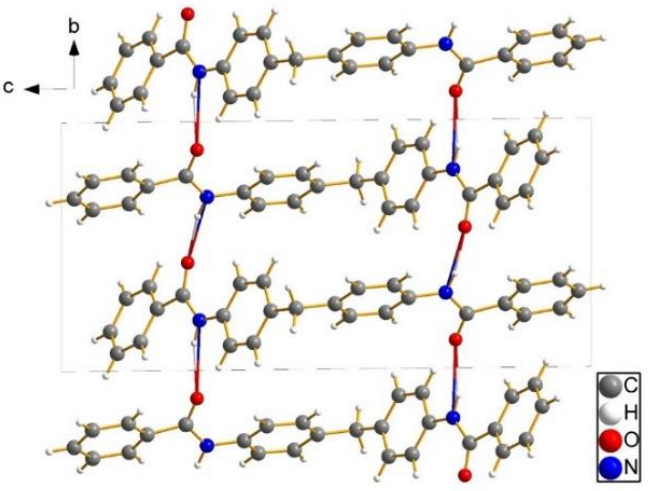

Figure 1. (a) Perspective view of an asymmetric unit of $\mathrm{C}_{27} \mathrm{H}_{22} \mathrm{~N}_{2} \mathrm{O}_{2}$ within a unit cell of BZ2. (b) Dense crystal packing of BZ2 molecules along the crystallographic a-axis (view along the crystallographic b-axis). (c) Crystal Packing of BZ2 molecules (view along the crystallographic a-axis) with hydrogen bonding networking (two-coloured bonds) running along the crystallographic b-axis.

a)

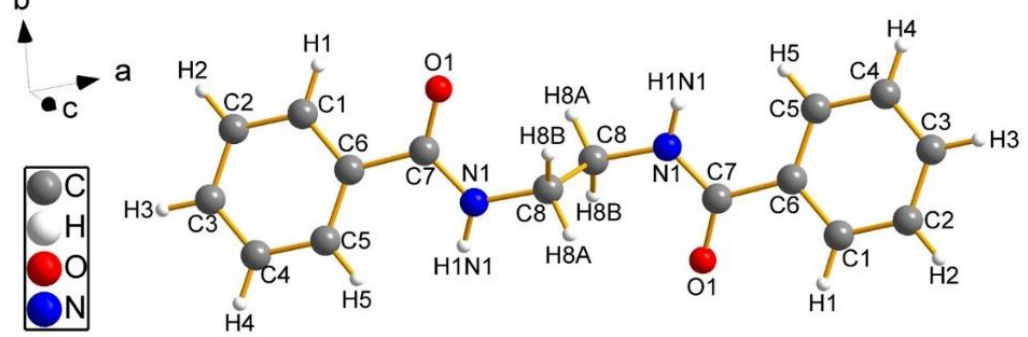

b)

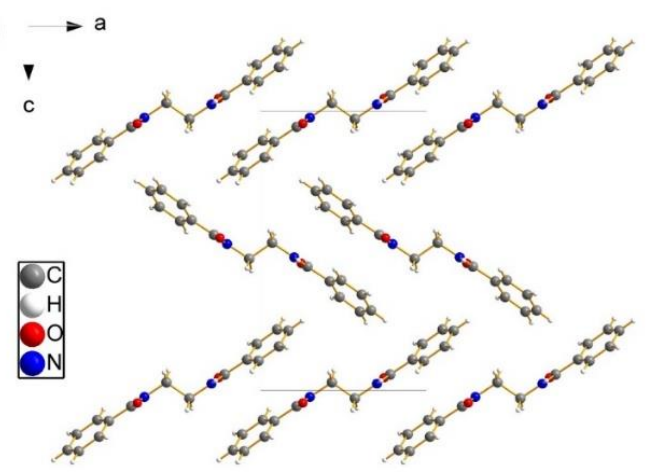

c)

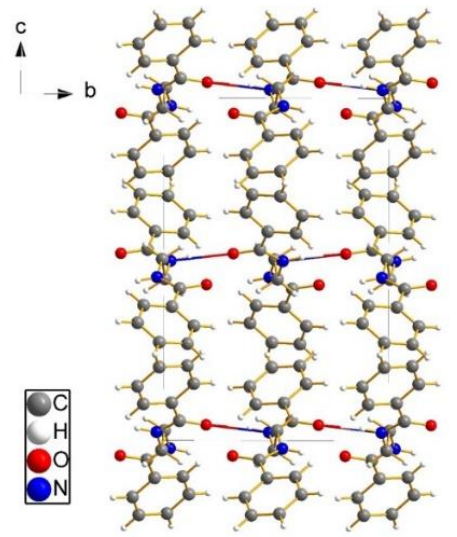

Figure 2. (a) Perspective view of a doubled asymmetric unit of $\mathrm{C}_{16} \mathrm{H}_{16} \mathrm{~N}_{2} \mathrm{O}_{2}$ within a unit cell of BZ6 (a centre of inversion lies between the two C8 atoms). (b) Dense crystal packing of BZ6 molecules along the crystallographic a-axis (view along the crystallographic b-axis). (c) Crystal Packing of BZ6 molecules (view along the crystallographic a-axis) with hydrogen bonding networking (two-coloured bonds) running along the crystallographic b-axis. 


\subsection{Spectral Studies}

The presence of different functional groups in both series was confirmed using spectroscopic techniques (FTIR, ${ }^{1} \mathrm{H}$ and ${ }^{13} \mathrm{C}$ NMR). FTIR spectral data of ferrocenyl amides and organic analogues was in accordance with the archetypal crystal structures as tabulated in Tables S1 and S2.

In ferrocenyl amides, $\mathrm{N}-\mathrm{H}$ stretch was observed in the range of $3304-3390 \mathrm{~cm}^{-1}$ confirming the amide linkage while aromatic $\mathrm{CH}$ in the region of $2956-3095 \mathrm{~cm}^{-1}$. The reduction in the value of carbonyl stretch confirms the presence of an amide linkage which is in the range of $1628-1651 \mathrm{~cm}^{-1}$. Fe-Cp stretch appeared in the range of $500-512 \mathrm{~cm}^{-1}$ (Table S1).

FTIR spectral data of organic analogues showed that an $\mathrm{N}-\mathrm{H}$ peak appeared in the range of $3300-3391 \mathrm{~cm}^{-1}$ which confirms the presence of an amide linkage in the respective product. $\mathrm{C}=\mathrm{C}$ of aromatic rings appeared in the region of $1487-1601 \mathrm{~cm}^{-1}$ while an aromatic $\mathrm{CH}$ stretch emerged in the region of $3047-3070 \mathrm{~cm}^{-1}$ (Table S2). The successful synthesis of corresponding amides is also envisaged by close inspection of the stretching modes associated with the acyl halide precursors. The carbonyl stretch for acid halides appears at $1775-1810 \mathrm{~cm}^{-1}$ in the starting precursors, which in the case of amide formation appeared in the region of $1630-1670 \mathrm{~cm}^{-1}$. The reduction of the carbonyl stretching mode associated with the amide linkages which is higher in the case of acyl halides confirms the successful synthesis of the desired product. Besides, the $\mathrm{C}-\mathrm{Cl}$ stretch in the acyl halide appears in the range of $550-730 \mathrm{~cm}^{-1}$ and it disappeared upon product formation further endorsing the formation of the respective amide.

Further confirmation of the amide linkage within the scaffold was examined using ${ }^{1} \mathrm{H}$ and ${ }^{13} \mathrm{C}$ NMR spectroscopic techniques. Due to issues with low solubility, NMR spectral data could not be acquired for all compounds, therefore data of a few representative compounds of the series is given in the Supplementary Information (Tables S3 and S4).

The proton NMR spectral data was in accordance with the proposed structures. The signal of amide protons was observed at $10.5 \mathrm{ppm}$ in ferrocenyl amides confirming the formation of the synthesised compound. Ferrocene protons appeared at 4.2-4.6 ppm comprising of three signals i.e., a singlet for unsubstituted $\mathrm{Cp}$ ring and two triplets for the substituted $\mathrm{Cp}$ ring. Aromatic protons appeared in the range of $6.6-8.3 \mathrm{ppm}$.

In organic analogues, signals of amide protons appeared in the range of $10 \mathrm{ppm}$ whereas aromatic protons appeared in the range of 7-8 ppm. The shift of the amide proton signal in the downfield region confirms the presence of hydrogen bonding within the amide linkage.

The ${ }^{13} \mathrm{C}$ NMR spectral data of ferrocenyl amide describes the carbonyl carbon gives the most downfield signal appearing at $164 \mathrm{ppm}$. The carbon attached to the ether appeared at $141 \mathrm{ppm}$ and the rest of aromatic carbons appeared at $137-116 \mathrm{ppm}$. The carbon of ferrocene appeared at $86.7 \mathrm{ppm}$. The unsubstituted $\mathrm{Cp}$ ring appeared at $69 \mathrm{ppm}$ while the substituted $\mathrm{Cp}$ ring showed two signals at 68 and $65 \mathrm{ppm}$. In the organic analogues, the carbonyl carbon was observed in the range of 165.7-166 ppm. This carbon is the most downfield confirming the presence of an amide group.

\subsection{Biological Activities}

Ferrocene and its derivatives are well suited for biological applications in conjugation with biomolecules because of their non-toxicity, membrane penetration of ferrocenyl group, stability, easy accessibility and promising electrochemical properties $[27,28]$. Different biological tests were performed like antioxidant activities, enzyme inhibition activities and antibacterial activities. The results of an overall comparative trend of different biological activities of ferrocenyl amides (FB1-FB13) and organic analogues (BZ1-BZ13) are presented in Table 3. 
Table 3. Biological activities of ferrocenyl amides (FB1-FB13) and organic analogues (BZ1-BZ13).

\begin{tabular}{|c|c|c|c|c|c|c|c|c|c|c|}
\hline \multirow[t]{2}{*}{ Sample } & \multicolumn{2}{|c|}{$\begin{array}{l}\text { Antioxidant Activity } \\
\text { at } 200 \mathrm{ppm}(\%)\end{array}$} & \multicolumn{4}{|c|}{$\begin{array}{c}\text { Enzyme Inhibition Activity at } 200 \\
\text { ppm (\%) }\end{array}$} & \multicolumn{4}{|c|}{$\begin{array}{l}\text { Antimicrobial Activity at } 200 \mathrm{ppm} \\
\text { (Zone of Inhibition in } \mathrm{mm} \text { ) }\end{array}$} \\
\hline & $\begin{array}{l}\text { DPPH } \\
\text { Assay }\end{array}$ & $\begin{array}{l}\mathrm{H}_{2} \mathrm{O}_{2} \\
\text { Assay }\end{array}$ & $\begin{array}{l}\text { GLU } \\
\text { Assay }\end{array}$ & $\begin{array}{l}\text { AMY } \\
\text { Assay }\end{array}$ & $\begin{array}{c}\text { ACE } \\
\text { Assay }\end{array}$ & $\begin{array}{c}\text { BCE } \\
\text { Assay }\end{array}$ & $\begin{array}{c}\text { S. } \\
\text { aureus }\end{array}$ & E. coli & $\begin{array}{c}M . \\
\text { luteus }\end{array}$ & $\begin{array}{c}E . \\
\text { aerogenes }\end{array}$ \\
\hline FB1 & 95.7 & 45.0 & 51.9 & 42.7 & 0.0 & 5.2 & 15.0 & 5.0 & 0.0 & 0.0 \\
\hline FB2 & 85.0 & 30.8 & 56.1 & 37.4 & 0.0 & 2.2 & 8.0 & 8.0 & 5.0 & 4.0 \\
\hline FB3 & 96.5 & 80.0 & 68.6 & 61.5 & 0.0 & 1.3 & 5.0 & 8.0 & 4.0 & 4.0 \\
\hline FB6 & 85.5 & 52.6 & 19.2 & 42.8 & 0.0 & 11.7 & 4.0 & 4.0 & 0.0 & 4.0 \\
\hline FB7 & 89.6 & 76.0 & 46.4 & 36.9 & 0.0 & 2.1 & 6.0 & 5.0 & 0.0 & 0.0 \\
\hline FB8 & 81.2 & 42.7 & 49.6 & 37.0 & 3.4 & 10.5 & 8.0 & 8.0 & 5.0 & 4.0 \\
\hline FB9 & 82.2 & 45.1 & 52.0 & 29.0 & 0.0 & 2.3 & 4.0 & 5.0 & 0.0 & 0.0 \\
\hline FB10 & 91.6 & 60.5 & 52.5 & 25.8 & 0.0 & 2.2 & 14.0 & 5.0 & 0.0 & 0.0 \\
\hline FB13 & 84.2 & 53.2 & 80.8 & 17.9 & 12.6 & 3.4 & 8.0 & 4.0 & 0.0 & 4.0 \\
\hline BZ1 & 82.1 & 70.2 & 69.0 & 14.8 & 31.4 & 9.9 & 0.0 & 0.0 & 0.0 & 0.0 \\
\hline BZ2 & 76.3 & 56.4 & 70.5 & 24.0 & 22.5 & 46.7 & 0.0 & 0.0 & 0.0 & 0.0 \\
\hline BZ3 & 82.8 & 79.9 & 86.6 & 5.9 & 37.9 & 0.1 & 0.0 & 0.0 & 0.0 & 0.0 \\
\hline BZ4 & 83.2 & 70.9 & 62.5 & 7.9 & 33.9 & 0.1 & 0.0 & 0.0 & 0.0 & 0.0 \\
\hline BZ5 & 81.2 & 86.3 & 4.5 & 8.6 & 7.1 & 0.0 & 0.0 & 0.0 & 0.0 & 0.0 \\
\hline BZ6 & 82.5 & 88.3 & 60.4 & 13.3 & 39.2 & 0.0 & 0.0 & 0.0 & 0.0 & 0.0 \\
\hline BZ7 & 83.9 & 75.6 & 67.0 & 17.2 & 13.0 & 0.0 & 0.0 & 0.0 & 0.0 & 0.0 \\
\hline BZ8 & 75.4 & 77.5 & 48.9 & 20.9 & 21.8 & 0.0 & 0.0 & 0.0 & 0.0 & 0.0 \\
\hline BZ9 & 75.9 & 85.6 & 24.6 & 5.8 & 28.1 & 0.0 & 0.0 & 0.0 & 0.0 & 0.0 \\
\hline BZ10 & 85.1 & 86.1 & 23.5 & 8.2 & 19.0 & 6.0 & 0.0 & 0.0 & 0.0 & 0.0 \\
\hline BZ11 & 77.3 & 44.7 & 71.6 & 14.8 & 23.9 & 0.0 & 0.0 & 0.0 & 0.0 & 0.0 \\
\hline BZ12 & 83.4 & 77.0 & 73.0 & 17.2 & 24.5 & 2.7 & 0.0 & 0.0 & 0.0 & 0.0 \\
\hline BZ13 & 79.0 & 77.7 & 56.3 & 20.9 & 12.2 & 0.3 & 0.0 & 0.0 & 0.0 & 0.0 \\
\hline Ascorbic acid & 94.2 & 91.4 & NA & NA & NA & NA & NA & NA & NA & NA \\
\hline Acarbose & NA & NA & 95.4 & 94.3 & NA & NA & NA & NA & NA & NA \\
\hline $\begin{array}{l}\text { Galantamine } \\
\text { hydrobromide }\end{array}$ & NA & NA & NA & NA & 94.7 & 91.5 & NA & NA & NA & NA \\
\hline Kanamycin & NA & NA & NA & NA & NA & NA & 25.0 & 20.0 & 26.0 & 22.0 \\
\hline
\end{tabular}

Where NA, GLU, AMY, ACE, BCE, S. aureus, E. coli, M. luteus and E. aerogenes represents not applicable, $\alpha$-glucosidase, $\alpha$-amylase, acetylcholinesterase, butyrylcholinesterase, Staphylococcus aureus, Escherichia coli, Micrococcus luteus and Enterobacter aerogenes (also known as Klebsiella aerogenes) respectively.

Antioxidant activity was determined by DPPH and hydrogen peroxide free radical scavenging assay and the results are presented in Figures S1 and S2. All of the compounds exhibited significant activities in both assays, however, ferrocenyl amides showed more activity as compared to the organic analogues. The highest activity was exhibited by FB3 (96.5\%) and BZ6 (88.6\%) respectively for ferrocenyl amides and organic analogues as compared to ascorbic acid (94.2\%) used as a positive control. The products which are sterically less hindered can easily donate their labile protons subsequently showing higher activities $[29,30]$.

Alpha glucosidase and alpha amylase enzyme inhibition activity are carried out to slow down the absorption of glucose in the blood by blocking the binding sites of these enzymes as high activity of these enzymes may result in chronic diseases like diabetes. In alpha glucosidase enzyme inhibition, FB12 $(80.8 \%)$ and BZ3 (86.6\%) exhibited prominent activities being highest in their respective groups. These results were compared to acarbose served as a positive control with $95.4 \%$ inhibition (Figures S3 and S4). These activities might be due to the presence of aliphatic as well as ether-based linkages in the compounds. On the other hand, in alpha amylase assay the highest activity was observed in the case of FB11 (64.7\%) and FB3 (61.5\%) Figure S5, while organic analogues did not show significant activity compared to ferrocenyl amides owing to the absence of the ferrocene moiety, Figure S6.

Acetylcholinesterase and Butyrylcholinesterase hydrolyse acetylcholine which is necessary for the proper functioning of the autonomic nervous system. During the neurodegenerative disorders like Alzheimer's disease, cholinergic transmission in synapsis, is suppressed. Acetylcholine is produced in lower amounts in these patients. Therefore, the production of these enzymes is inhibited to increase the 
amount of acetylcholine in the body. Acetylcholinestrase inhibitors block this enzyme thus inhibiting the hydrolysis of acetylcholine into acetate and choline hence prolonging its duration of action. In the case of ferrocenyl amides, slight inhibition activity was observed for FB13 (11.7\%) and FB12 (12.6\%). On the other hand, the organic analogues showed comparatively better enzyme inhibition activities as compared to ferrocenyl amides being highest for BZ6 (39.2\%). These results were compared to galantamine hydrobromide used as a positive control with $94.7 \%$ enzyme inhibition. If the substitution is changed, there may be an increase in activity, Figure S7. While in the butyrylcholinesterase assay, only FB2 showed moderate activity which might be due to the presence of reactive ferrocene moiety and flexibility in the structure due to aromatic rings separated by a methyl group, Figure S8 [23].

Lastly, antibacterial activity was observed using two types of Gram-positive bacteria i.e., Staphylococcus aureus and Micrococcus luteus and two types of Gram-negative bacteria i.e., Escherichia coli and Enterobacter aerogenes (also known as Klebsiella aerogenes) at 200 ppm concentration. Gram-positive bacteria were observed to have more activity as compared to Gram-negative bacteria owing to the difference in their cell walls properties. Organic analogues showed no activity as compared to ferrocenyl amides as organometallic forms are more toxic in comparison to their organic equivalents (Figure S9 and Figure S10) [31]. In ferrocenyl amides, the highest activity was observed for the compound FB1 with a $15 \mathrm{~mm}$ zone of inhibition for Gram-positive bacteria. Sidewise, in the case of Gram-negative bacteria, the compound FB10 exhibited highest antibacterial activity with a $10 \mathrm{~mm}$ zone of inhibition. Kanamycin was used as a positive control which showed a $25 \mathrm{~mm}$ and a $25 \mathrm{~mm}$ zone of inhibitions for Gram-positive and Gram-positive bacteria, respectively.

\section{Conclusions}

Two series of amides were synthesised successfully by using a condensation method. The synthesised amides were characterised by elemental, spectroscopic (FT-IR and NMR), and single crystal X-ray diffraction analyses. Ferrocenyl amides and their organic analogues were investigated for various biological activities. The highest activity was observed for BZ5 while BZ9 and FB8 also showed moderate activities for DPPH free radical scavenging activity. Total antioxidant capacity was the highest for FB1 and FB3. BZ5, BZ9 and BZ10 showed enhanced activities in response to $\mathrm{H}_{2} \mathrm{O}_{2}$ scavenging activity. In the alpha glucosidase enzyme inhibition assay, maximum activity was observed for FB13 and BZ3 for their respective series whereas FB3 and FB12 also showed reasonable activities. In the case of the alpha amylase enzyme inhibition assay, FB3, FB11 and BZ2 showed marked activities. AChE and BChE enzyme inhibition activities showed evident results in case of BZ3, BZ6 and BZ2. Ferrocenyl amides were observed to have stronger antibacterial properties as compared to the organic analogues and pronounced activities were observed in case of Gram-positive bacteria as compared to Gram-negative bacteria.

Crystal structures of the organic analogues BZ2 and BZ6 were solved by single crystal X-ray diffraction. BZ2 crystallises in the triclinic crystal system, whereas BZ6 crystallises in the orthorhombic crystal system. The packing scheme of the molecules in both crystal structures is defined and can be explained by hydrogen bonding networks and additional van-der-Waals interactions. Although the crystal structures of similar BZ analogues could not be determined, it can be expected that the molecular arrangements are determined in a similar manner by hydrogen bonding networks.

As crystal structures could only be solved for BZ2 and BZ6, a direct linkage between crystal structures and biological activities could not be drawn, since BZ2 and BZ6 do not show any prominent difference in their biological activity in comparison to the other organic analogues. Therefore, further investigation of the crystal structures of ferrocenyl amides and their organic analogues is required in order to determine the exact molecular configuration which could then be linked to the observed biological activities.

Supplementary Materials: The following are available online at http://www.mdpi.com/2073-4352/10/6/480/s1, detailed information about the synthesis, Figure S1: DPPH free radical scavenging activity, Figure S2: Hydrogen peroxide scavenging activity, Figure S3: Alpha glucosidase enzyme inhibition activity of ferrocenyl amides, 
Figure S4: Alpha glucosidase enzyme inhibition activity of organic analogues, Figure S5: Alpha amylase enzyme inhibition activity of ferrocenyl amides, Figure S6: Alpha amylase enzyme inhibition activities of organic analogues, Figure S7: Acetylcholinesterase enzyme inhibition activities, Figure S8: Butyrylcholinesterase enzyme inhibition activities, Figure S9: Antibacterial activity of gram-negative bacteria, Figure S10: Antibacterial activity of gram-positive bacteria, Table S1: FTIR $\left(\mathrm{cm}^{-1}\right)$ spectral data of ferrocenyl amides (FB1-FB13), Table S2: FTIR $\left(\mathrm{cm}^{-1}\right)$ spectral data of organic analogues (BZ1-BZ13), Table S3: ${ }^{1} \mathrm{H}$ NMR spectral data of ferrocenyl amide and organic analogues, Table S4: ${ }^{13} \mathrm{C}$ NMR spectral data of ferrocenyl amides and organic analogues. Supplementary data of the crystal structure and refinement, like full bond lengths, bond angles, dihedral angles, and anisotropic displacement parameters, have been deposited, BZ2 (CCDC deposition \#1824487) and BZ6 (CCDC deposition \#1824488). These data can be obtained, free of charge, using the link www.ccdc.cam.ac.uk or from the CCDC, 12 Union Road Cambridge CB2 1EZ, UK; Fax: +44-1223-336033; e-mail: deposit@ccdc.cam.ac.uk.

Author Contributions: Conceptualisation, Z.A. and N.Z.A.; methodology, S.W.A.; software, S.J.S. and N.Z.A.; validation, S.J.S., S.W.A. and H.I.; formal analysis, S.J.S., H.I. and Z.A.; investigation, S.W.A., H.I., and N.Z.A.; resources, Z.A. and S.J.S.; data curation, S.J.S. and M.S.; writing-original draft preparation, N.Z.A., M.E. and S.W.A.; writing - review and editing, M.E., N.Z.A., S.W.A. and Z.A.; visualisation, M.S. and B.M.; supervision, Z.A. and N.Z.A.; project administration, Z.A. and B.M.; funding acquisition, M.E. All authors have read and agreed to the published version of the manuscript.

Acknowledgments: N.Z.A. is highly grateful to Brigham Young University for providing the technical support and laboratory facilities during the collaborative stay at Provo, UTAH, USA. M.E. acknowledges DESY for funding in order to make this publication open access. The authors further acknowledge the financial grant from the Higher Education Commission, Islamabad Pakistan.

Conflicts of Interest: The authors declare no conflict of interest.

\section{References}

1. Kauffman, G.B. The discovery of ferrocene, the first sandwich compound. J. Chem. Educ. 1983, 60, 185. [CrossRef]

2. Neto, A.F.; Pelegrino, A.C.; Darin, V.A. Ferrocene: 50 years of transition metal organometallic chemistry-from organic and inorganic to supramolecular chemistry. ChemInform 2004, 35. [CrossRef]

3. Pauson, P.L. Ferrocene-how it all began. J. Organomet. Chem. 2001, 637, 3-6. [CrossRef]

4. Lozano, K.; Barrera, E. Nanofiber-reinforced thermoplastic composites. I. Thermoanalytical and mechanical analyses. J. Appl. Polym. Sci. 2001, 79, 125-133. [CrossRef]

5. Ornelas, C. Application of ferrocene and its derivatives in cancer research. New J. Chem. 2011, 35, $1973-1985$. [CrossRef]

6. Hüsken, N.; Gasser, G.; Köster, S.D.; Metzler-Nolte, N. “Four-potential” ferrocene labeling of PNA oligomers via click chemistry. Bioconjugate Chem. 2009, 20, 1578-1586. [CrossRef]

7. Amer, W.A.; Wang, L.; Amin, A.M.; Ma, L.; Yu, H. Recent progress in the synthesis and applications of some ferrocene derivatives and ferrocene-based polymers. J. Inorg. Organomet. Polym. Mater. 2010, 20, $605-615$. [CrossRef]

8. El Arbi, M.; Pigeon, P.; Top, S.; Rhouma, A.; Aifa, S.; Rebai, A.; Vessières, A.; Plamont, M.A.; Jaouen, G. Evaluation of bactericidal and fungicidal activity of ferrocenyl or phenyl derivatives in the diphenyl butene series. J. Organomet. Chem. 2011, 696, 1038-1048. [CrossRef]

9. Harry, A.G.; Butler, W.E.; Manton, J.C.; Pryce, M.T.; O’Donovan, N.; Crown, J.; Rai, D.K.; Kenny, P.T. The synthesis, structural characterization and in vitro anti-cancer activity of novel 1-alkyl-1'-N-para-(ferrocenyl) benzoyl dipeptide esters. J. Organomet. Chem. 2014, 757, 28-35. [CrossRef]

10. Lectka, T. The Amide Linkage. Selected Structural Aspects in Chemistry, Biochemistry, and Materials Science. Herausgegeben von Greenberg, A., Breneman, C.M., und Liebman, J.F. Angew. Chem. 2001, 113, 4429-4430. [CrossRef]

11. Kovács, E.; Rózsa, B.; Csomos, A.; Csizmadia, I.G.; Mucsi, Z. Amide activation in ground and excited states. Molecules 2018, 23, 2859. [CrossRef] [PubMed]

12. Mucsi, Z.; Tsai, A.; Szori, M.; Chass, G.A.; Viskolcz, B.; Csizmadia, I.G. A Quantitative Scale for the Extent of Conjugation of the Amide Bond. Amidity Percentage as a Chemical Driving Force. J. Phys. Chem. A 2007, 111, 13245-13254. [CrossRef] [PubMed]

13. Girgis, A.S.; Ellithey, M. Facile synthesis of non-steroidal anti-inflammatory active bisbenzamide-containing compounds. Bioorg. Med. Chem. 2006, 14, 8527-8532. [CrossRef] [PubMed] 
14. Carey, J.S.; Laffan, D.; Thomson, C.; Williams, M.T. Analysis of the reactions used for the preparation of drug candidate molecules. Bioorg. Med. Chem. 2006, 4, 2337-2347. [CrossRef] [PubMed]

15. Kaspar, A.A.; Reichert, J.M. Future directions for peptide therapeutics development. Drug Discov. Today 2013, 18, 807-817. [CrossRef]

16. Afrasiabi, R.; Kraatz, H.B. Stimuli-Responsive Supramolecular Gelation in Ferrocene-Peptide Conjugates. Chem. Eur. J. 2013, 19, 17296-17300. [CrossRef]

17. Sabapathy, R.C.; Bhattacharyya, S.; Leavy, M.C.; Cleland, W.E.; Hussey, C.L. Electrochemical and spectroscopic characterization of self-assembled monolayers of ferrocenylalkyl compounds with amide linkages. Langmuir 1998, 14, 124-136. [CrossRef]

18. Xie, Y.-S.; Zhao, H.-L.; Su, H.; Zhao, B.-X.; Liu, J.-T.; Li, J.-K.; Lv, H.-S.; Wang, B.-S.; Shin, D.-S.; Miao, J.-Y. Synthesis, single-crystal characterization and preliminary biological evaluation of novel ferrocenyl pyrazolo [1, 5-a] pyrazin-4 (5H)-one derivatives. Eur. J. Med. Chem. 2010, 45, 210-218. [CrossRef]

19. Sheldrick, G.M. SHELXT_-Integrated space-group and crystal-structure determination. Acta Cryst. A 2015, 71, 3-8. [CrossRef]

20. Sheldrick, G.M. Crystal structure refinement with SHELXL. Acta Cryst. C 2015, 71, 3-8. [CrossRef]

21. Müller, P. Practical suggestions for better crystal structures. Crystallogr. Rev. 2009, 15, 57-83. [CrossRef]

22. Keerthana, G.; Kalaivani, M.K.; Sumathy, A. $\alpha$-Amylase Inhibitor's Performance in the Control of Diabetes Mellitus: An Application of Computational Biology. Asian J. Pharm. Clin. Res. 2013. [CrossRef]

23. Jabeen, F.; Oliferenko, P.V.; Oliferenko, A.A.; Pillai, G.G.; Ansari, F.L.; Hall, C.D.; Katritzky, A.R. Dual inhibition of the $\alpha$-glucosidase and butyrylcholinesterase studied by Molecular Field Topology Analysis. Eur. J. Med. Chem. 2014, 80, 228-242. [CrossRef] [PubMed]

24. da Silva, J.K.R.; Pinto, L.; Burbano, R.; Montenegro, R.C.; Guimarães, E.F.; Andrade, E.H.A.; Maia, J.G.S. Essential oils of Amazon Piper species and their cytotoxic, antifungal, antioxidant and anti-cholinesterase activities. Ind. Crops Prod. 2014, 58, 55-60. [CrossRef]

25. Valgas, C.; Souza, S.M.; Smânia, E.F.; Smânia, A., Jr. Screening methods to determine antibacterial activity of natural products. Braz. J. Microbiol. 2007, 38, 369-380. [CrossRef]

26. Zhao, K.Q.; Hu, P.; Xu, H.-B. 4-Formylphenyl 4-Ferrocenylbenzoate. Molecules 2001, 6, M247. [CrossRef]

27. Staveren, D.R.V.; Nolte, N.M. Bioorganometallic chemistry of ferrocene. Chem. Rev. 2004, 104, 5931-5986. [CrossRef]

28. Moriuchi, T.; Hirao, T. Highly ordered structures of peptides by using molecular scaffolds. Chem. Soc. Rev. 2004, 33, 294-301. [CrossRef]

29. Moukette, B.M.; Pieme, C.A.; Njimou, J.R.; Biapa, C.P.N.; Marco, B.; Ngogang, J.Y. In vitro antioxidant properties, free radicals scavenging activities of extracts and polyphenol composition of a non-timber forest product used as spice: Monodora myristica. Biol. Res. 2015, 48,1-17. [CrossRef]

30. Bonacorso, H.G.; Cavinatto, S.; Moraes, M.C.; Pittaluga, E.P.; Peroza, L.R.; Venturini, T.; Alves, S.H.; Stefanello, S.T.; Soares, F.A.; Martins, M.A. Synthesis, Structure Elucidation, Antioxidant and Antimicrobial Activity of Novel 2-(5-Trifluoromethyl-1H-pyrazol-1-yl)-5-(5-trihalomethyl-1H-pyrazol-1-yl-1-carbonyl) pyridines. J. Braz. Chem. Soc. 2015, 26, 2346-2361. [CrossRef]

31. Ali, S.; Badshah, A.; Ataf, A.A.; Lal, B.; Khan, K.M. Synthesis of 3-ferrocenylaniline: DNA interaction, antibacterial, and antifungal activity. Med. Chem. Res. 2013, 22, 3154-3159. [CrossRef]

(C) 2020 by the authors. Licensee MDPI, Basel, Switzerland. This article is an open access article distributed under the terms and conditions of the Creative Commons Attribution (CC BY) license (http://creativecommons.org/licenses/by/4.0/). 